\title{
The Promise and Peril of ANECDOtes in NeWS Coverage: AN ETHICAL ANALYSIS
}

By David A. Craig

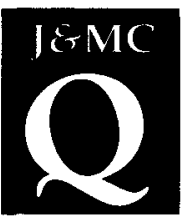

This article assesses the use of anecdotes in news coverage on ethical grounds, pointing both to their promise and to their potential dangers. The analysis draws on Craig's framework for analyzing news coverage of ethics; on Christians, Ferre, and Fackler's communitarian ethic; and on Gilligan's relationship-oriented ethic of care. Cases from news stories illustrate the ethical complexity of anecdote use. This study suggests how journalists can choose anecdotes more critically and points to an adaptation of the anecdotal form that is ethically supportable.

Journalists for print and broadcast media often use anecdotes about individuals to illustrate larger points. Research on the use of examples about individuals, such as anecdotes, in news coverage ${ }^{1}$ has shown that exemplars shape people's perceptions of social issues. But even journalists understand the difficulties posed by anecdotes. Gina Kolata, a science reporter for the New York Times, said:

I think anecdotes are actually almost too powerful. I always call it the "tyranny of the anecdote." You have to be really careful with anecdotes because people will remember the anecdote and it will mean more to them than anything else you say. So you have to be very, very careful, I think, about how you use them, but I think that they're so powerful that they sort of cry out to be used if they can. ${ }^{2}$

Rather than testing effects of anecdotes on audience understanding, as exemplification researchers have done, this article assesses the use of anecdotes on ethical grounds. It evaluates the ethical strengths and weaknesses of anecdotes as a journalistic device. The analytical groundwork for ethical evaluation comes from a framework used earlier for assessing news coverage of ethical issues; ${ }^{3}$ Christians, Ferre, and Fackler's communitarian media ethics; ${ }^{4}$ and Gilligan's relationship-oriented feminist ethic. ${ }^{5}$ These perspectives hold that news coverage should address topics at the individual level and within broader contexts as well.

J\&MC Quarterly

Vol. 80, No.4

Winter 2003

$802-817$

(92003 AEJMC
David A. Craig is an associate professor in the Gaylord College of Journalism and Mass Communication, University of Oklahoma. 
The three perspectives will be used to analyze some news coverage of human embryo research, physician-assisted suicide, and the practices of health maintenance organizations. The anecdotes used as cases for analysis are from major print and broadcast news organizations, organizations that presumably reflect the state of the art in use of anecdotes in reporting, however flawed that art may be. This article will also discuss how journalists can choose anecdotes more critically, building on Boeyink's discussion of casuistry in journalistic decision making. ${ }^{6}$ Finally, it suggests an adaptation of the anecdotal form that is ethically supportable.

Studies of framing effects ${ }^{7}$ have found that episodic and human interest frames-in which anecdotes are often an element-affect audiences' thinking in important ways. In particular, Iyengar ${ }^{8}$ found that

Literature Review episodic framing, focusing news coverage on individuals and events, tends to prompt television news audiences to attribute responsibility for issues to individuals rather than social factors. Valkenburg, Semetko, and de Vreese ${ }^{9}$ found that crime stories framed in human interest terms prompted readers to emphasize emotions and implications for individuals more often, and to recall less information about an issue.

The literature on exemplification, because it focuses explicitly on the use and impact of examples, carries particular significance for an ethical analysis of anecdotes. Zillmann and Brosius ${ }^{10}$ address the problematic nature of anecdotes in noting that the concept of exemplification calls for the representation of groups of events "by single events that are typical and characteristic of the group. Exemplification by atypical and uncharacteristic events is deemed inappropriate because it fails to provide reliable information about the group." 11 Given the inherent difficulties of accurate representation through anecdotes, the prevalence of anecdotes in journalism stands out as an ethical issue.

Psychological research ${ }^{12}$ shows that exemplification can overwhelm the influence of base-rate information-broader figures or statements about the frequency or typicality of an event. In one study, subjects shown an article about a welfare recipient and an interview with a prison guard changed their minds about the population as a whole, regardless of what kind of information they received about how typical the case was. ${ }^{13}$ Mass communication researchers have found that different distributions of exemplars have differing effects on audience perception of issues. Zillmann, Perkins, and Sundar ${ }^{14}$ varied the ratio of exemplars to counterexemplars in a story about keeping weight off after dieting. The exemplars either all followed the focus of the story (selective exemplification), or were proportional to the situation in the broader population (representative), or disproportionately favored one side (blended). Audiences' perception of the overall incidence of weight regaining proved most accurate for the representative condition and least accurate for the selective. Likewise, Brosius and Bathelt ${ }^{15}$ found that the perception of majority and minority opinions on public issues followed the distribution of exemplars. Zillmann et al. ${ }^{16}$ found that changes in the kinds of exemplars used in a news report on the plight of family farmers altered readers' perceptions of the prevalence of family farm failures. 
Other research has examined the impact of using examples from extraordinary or highly emotional cases. Gibson and Zillmann ${ }^{17}$ found that estimates of the frequency of deaths in carjackings increased as exemplars were tilted more and more toward the unusual case of a fatal carjacking. A study of television new $\mathrm{s}^{18}$ found that exemplification using emotional victims fostered perceptions that food poisoning problems and random violence were more severe than when unemotional or no victim exemplification was used.

Even the use of quotations in exemplars, a conventional journalistic practice, has been found to influence audiences. Gibson and Zillmann found that direct, one-sided personal testimony in print reports changed perceptions of amusement park safety. ${ }^{19}$ They also found that personal testimony about the plight of family farmers swayed readers' views. ${ }^{20} \mathrm{In}$ addition, studies have found effects from the use of both threatening images and innocuous images, for example, changes in perception of risk of skin cancer. ${ }^{21}$ Findings about use of images are relevant to the evaluation of anecdotes in broadcast news because of its dependence on images.

Viewed as a body, empirical studies on the power of exemplars indicate a need for careful consideration of the ethical implications of anecdote choice.

Analytical Perspectives
Three analytical perspectives are useful tools for assessing these ethical implications because they point both to the potential ethical good and the ethical dangers of anecdote use.

A framework developed previously for studying coverage of news with an ethical dimension involves evaluating stories based on how thoroughly they portray the ethical issues relevant to a topic, the parties connected with those issues, the levels at which the ethical issues play out (individual, organizational/institutional, professional, and social), and the legal backdrop for those issues. ${ }^{22}$ Although each story about ethicsladen topics cannot be expected to address all four of these elements comprehensively, coverage that addresses these areas well is considered to be ethical. The normative assumptions about journalism in this framework are in keeping with social responsibility ${ }^{23}$ and communitarian ${ }^{24}$ press theory, both of which emphasize the importance of not merely reporting events but also serving society. ${ }^{25}$

The attention to levels of analysis reflects the importance of portraying individuals in news coverage. News coverage should include the ways that individuals and families are affected by decisions or eventssuch as a health maintenance organization's decision about whether to approve or deny coverage for a kind of cancer treatment. Anecdotes shine light on the difficulties that individuals face, and as such they are tools of ethical journalism. The importance of the individual notwithstanding, journalists should go beyond that level to examine issues at the organizational/institutional, professional, and social levels. Attention to only one level of analysis, in an in-depth piece or a body of coverage, falls short of the moral obligation of journalists. In this light, anecdotes are morally a double-edged sword. While they can bring attention to the 
plight of individuals in riveting fashion, and even place that plight in institutional, professional, and social contexts, the attention remains on a representative, or perhaps unrepresentative, individual or family, as exemplification studies have shown.

Furthermore, previous work suggests that news coverage should include an array of sources, including neither exclusively professionals (such as doctors or businesspeople) or nonprofessionals (patients or customers). Good anecdotes, although they focus on an individual, may point out how that individual interacts with other people, as well as with organizations and institutions. Attention to a range of relevant parties at a variety of levels, both in the anecdote and elsewhere in the story, can mitigate the potential ethical harm from anecdotes' narrow focus. But the exemplification literature suggests that the anecdote still would have power to shape readers' or viewers' perception of the broader issue.

Christians, Ferre, and Fackler's communitarian media ethic ${ }^{26}$ also provides ethical justification for using anecdotes to highlight the situations of individuals while it draws attention to the limitations of anecdotes. The idea of mutuality is central to this perspective, which has a variety of intellectual underpinnings including communitarian political theory and theology. Mutuality views humans as having their identity in relation to others and living both for others and themselves. The relationship of persons and communities takes priority over either alone. This ethic is profoundly concerned with both society and the individual. The priority of justice creates a profound interest in the needs of the hurting or marginalized. "A press nurtured by communitarian ethics requires more of itself than fair treatment of events deemed worthy of coverage. Under the notion that justice itself-and not merely haphazard public enlightenment-is a telos of the press, the news-media system stands under obligation to tell the stories that justice requires."27 Part of telling "the stories that justice requires" involves telling the stories of individuals. This is because justice addresses fair treatment of individuals. One of the most powerful ways, in fact, to draw attention to such individuals is through the telling of their stories, in words and images, in print and broadcast media.

Even as it provides an ethical underpinning for use of anecdotes, communitarian media ethics, with its deeply grounded concern for the good of society, calls into question the structure and choice of anecdotes. Again, this ethic does support the use of compelling individual cases to highlight broader social injustices. However, sloppy use of anecdotes can undermine an effort to portray the broader issue, not simply because of the natural tendency of anecdotes to highlight individuals, but also because the particular choice of individuals can skew understanding toward one side of a controversial issue, resulting potentially in neglect of social justice. The issue is not formulaic balance in news coverage; communitarian ethics calls for more than "fair treatment of events." 28 Consonant with Durham's notion of "strong objectivity," ${ }^{29}$ Christians, Ferre, and Fackler call for highlighting the perspectives of the marginalized and, where needed, giving those perspectives attention that is out of balance with the play given to the stories of the powerful. However, since communitarian ethics also implies a concern for faithful portrayal of the 
whole community, it implies a need to portray the breadth of the community's concern.

Gilligan's feminist ethic of care ${ }^{30}$ supports the use of anecdotes because it, too, is concerned with persons in relationships. This perspective, developed out of psychological studies of women's distinctive conceptions of morality, underlines the importance of relationships and responsibilities. Discussing one of her interviewees, Gilligan writes: "Her world is a world of relationships and psychological truths where an awareness of the connection between people gives rise to a recognition of responsibility for one another, a perception of the need for response." Commenting on how another interviewee viewed activities of care, she writes: "The ideal of care is thus an activity of relationship, of seeing and responding to need, taking care of the world by sustaining the web of connection so that no one is left alone. ${ }^{\prime \prime 2}$ This ethic of care in relationships, however, is not relevant only to women, Gilligan argues. "To admit the truth of the women's perspective to the conception of moral development is to recognize for both sexes the importance throughout life of the connection between self and other, the universality of the need for compassion and care." 33

Anecdotes are ethically significant in the context of this perspective because they can help to portray the web of personal relationships and responsibilities involved in ethical situations. Anecdotes can dramatically represent the difficulties that individuals, including women facing illnesses such as breast cancer, face in relation to their families and others outside their families, such as physicians. ${ }^{34}$ In fact, use of anecdotes is in keeping with the attention to particulars that Gilligan found women bringing to their moral analysis. She discusses what happens when women go beyond hypothetical dilemmas:

However, the reconstruction of the dilemma in its contextual particularity allows the understanding of cause and consequence which engages the compassion and tolerance repeatedly noted to distinguish the moral judgments of women. Only when substance is given to the skeletal lives of hypothetical people is it possible to consider the social injustice that their moral problems may reflect and to imagine the individual suffering their occurrence may signify or their resolution engender. ${ }^{35}$

This passage implies that anecdotes may awaken attention both to the suffering of individuals and the social context of their difficulties. It suggests that, despite the danger of distortion of the broader picture that the exemplification literature suggests, deep concern for the people behind issues that journalists report may arise only through telling the stories of individuals.

Even as it underpins the ethical value of anecdotes, the ethic of care also implies a need for careful attention to what anecdotes are chosen and what they portray. It implies a need for accurate understanding of responsibilities of individuals in the broader context of society, so that the web of relationships and people's responsibilities within them is 
rightly understood. All three perspectives suggest that anecdotes are best when they situate individuals they mention in the broader context of the issues being discussed. These three perspectives all draw attention to the value of the individual and therefore imply that it is ethically justifiable to use anecdotes to draw attention to the needs and concerns of individuals. The communitarian ethic and the ethic of care complement the ethics coverage framework by emphasizing the individual in relationships. Communitarianism puts priority on the hurting and marginalized. The ethic of care draws attention to the importance of the circumstances of the lives of individuals in prompting a depth of concern for them. Even as they draw attention to the individual, however, all three perspectives emphasize the need to think beyond the individual to the broader contexts of a problem, thereby implying that anecdotes should be carefully chosen for how they may limit or draw attention to these contexts.

These three analytical perspectives will be applied to three anecdotes taken from larger bodies of stories about human embryo research, physician-assisted suicide, and HMOs, all topics that have received attention from the media and professionals during the past decade. These topics lend themselves to powerful use of anecdotes because of their life-and-death import. Even though both the exemplification literature and the analytical perspectives used here suggest this power may be a mixed blessing, it is appropriate to study these kinds of topics because of the priority that journalists place on powerful, compelling anecdotes.

Stories used here were published or aired during a key period of public discourse on each topic. For human embryo research, this was 1994-1995, amid federal debate on the subject. For physician-assisted suicide, it was 1997-1999, which encompassed a Supreme Court ruling that there is no general constitutional right to assisted suicide, passage of law in Oregon legalizing the practice, and the trial of Dr. Jack Kevorkian for euthanasia. For health maintenance organizations, 1997-1998 was a time of increasing legal and political attention to HMO practices. For each topic, both print and broadcast stories that dealt significantly with the ethical dimension of the issue were examined. ${ }^{36}$

The anecdotes analyzed as cases were chosen for their vivid language and emotional power. In these respects, they represent the kinds of anecdotes that journalists strive to include in stories on many topics. Thus, while it is inescapable that they cannot fully represent the range of anecdote use, even in the topics studied, they represent an aspect of standard journalistic usage. They are, therefore, appropriate for ethical analysis of the strong and weak points in this usage. ${ }^{37}$ Although space limits consideration to one anecdote from each topic, both print and broadcast cases are included to make the ethical analysis more relevant to both.

George Strait used an anecdote to help illustrate an ABC TV news story about human embryo research, ${ }^{38}$ aired just after a federal advisory panel recommended that federal funding be used to pay for research on

Analysis of Cases 
human embryos. The story outlined arguments for and against human embryo research. This anecdote, shown in the middle of the piece, was the second of two that illustrated potential benefits of human embryo research. The story showed a girl born after genetic testing of her mother's embryos, and Strait talked with the girl's father. Strait described the treatment that enabled this girl to be born, against the backdrop of video that included shots of her:

This research on human embryos has vast potential, from improving fertility and contraceptives to better screening for genetic diseases. Take Brittany Abshire [baby is shown wearing a bow on her head and a fancy dress]. Her parents, Rene and David Abshire, were afraid they might never have a healthy baby. Their first child, Meaghan [face is shown close-up in a still portrait], died of a rare genetic disease called Tay-Sachs. They got help here at the Jones Institute, where doctors recently developed a way to test an embryo for defective genes. Her deformed embryos were discarded; only healthy ones were implanted through in vitro fertilization. The result is Brittany [the dressed-up baby is shown again]. ${ }^{39}$

By showing compelling video of real people affected by embryo research-especially children-Strait brought home the reality that this ethical topic touches individuals deeply. He thus drew attention to the individual level while remaining consistent with the ethic of care, by showing the web of family relationships in which the individuals are affected profoundly by decisions made about in vitro fertilization. In addition, he used professionals elsewhere in the story to show others involved in these kinds of cases, including a doctor at the institute the Abshires used. He thus represented a range of parties.

In this case, the communitarian ethic does not apply as strongly in the sense that the people involved were not poor or marginalized. But the decisions paralleled those faced by thousands of other families-all of whom, in communitarian terms, should be concerned about people who face similar situations. The story served to highlight the difficulties faced by couples seeking in vitro fertilization, and it pointed appropriately to ethical questions raised about embryo research as well as the benefits.

However, especially given television's ability to use emotional visuals, the use of anecdotes may overshadow broader issues. Strait's anecdote about the Abshire family ${ }^{40}$ used a still portrait of their nowdeceased child, Meaghan, and shots of dressed-up baby Brittany, born after tests of other embryos for genetic defects and the use of in vitro fertilization. The story also used as sources two doctors, a Catholic leader critical of embryo research, and a member of a National Institutes of Health panel on human embryo research. This sourcing shows that Strait was seeking to place the issue in broader organizational, professional, and social context. But shots of a child who died and of a cute, living baby may overshadow the discussion of the broader context, especially since 
this and the only other anecdote in the story were used to illustrate potential benefits to individuals.

The second anecdote examined came from an NBC Nightly News story reported by Mike Boettcher. After anchor Brian Williams' introduction, Boettcher opened his reporting this way:

MIKE BOETTCHER reporting: No matter what Barbara Oskamp does, no matter how simple the act, the terminally ill woman writes it down [video shows list of simple things she must write down to remember], otherwise she'll forget when she takes a bath, when she washes clothes. A brain tumor slowly is taking her memory as it takes her life, and she wants the option to end her suffering before the pain becomes unbearable [close-up of her].Shesupports Oregon's Death With Dignity Act, the only assisted suicide law in the nation.

Ms. BARBARA OSKAMP: I don't know I'd be brave enough to actually do it. But the feeling that I had a choice, if the pain, maybe, was too awful, just as I said before, gave me a feeling of relief. ${ }^{41}$

The use of this anecdote is commendable from the standpoint of the ethics coverage framework in that it drew attention to the difficulties of the terminally ill at the individual level. From the standpoint of communitarian ethics, with its priority of mutuality and its attention to the marginalized, it amounted to a call for better support-emotional and medical-for this woman and others like her. Similarly, through the lens of the ethic of care, this examination of the particulars of Oskamp's daily life might evoke empathy for her suffering and consideration of the justice of the system of care for her (as well as concern about what seems in this anecdote to be an absence of relationships).

However, again these perspectives point to ethical lapses. Oskamp's plight was heart-rending, and it likely would evoke empathy from the audience because she was suffering. However, the very power of this portrayal of suffering may obscure consideration of issues such as, at the professional level, the role of better pain management or counseling, and, at the social level, the implications of legal assisted suicide for people with disabilities and terminally ill individuals who cannot pay for insurance. Social-level issues would be particularly important in the communitarian ethic-which, while supporting the attention to Oskamp and the concerns her situation raised, would also call for more direct attention to these other areas. A doctor was quoted as raising concern about impact on the poor-also important context under the ethic of care -but this professional voice was not as compelling as Oskamp's.

The third anecdote case concerns HMOs, which have become controversial in recent years because of the impact of HMO cost controls on patients. One repeated feature in the HMO stories, particularly the television pieces, was the use of anecdotes that were sympathetic to patients dealing with the fallout of $\mathrm{HMO}$ cost controls and related issues. 
A lengthy story in the Los Angeles Times, part of a series on "The HMO Backlash" in Ventura County, opened with that kind of account:

Norma Barry had been treated by Simi Valley family doctor Elvin Gaines all her life. She trusted him so much he delivered both of her babies.

She believed in his judgment to such a degree that she never argued when Gaines prescribed common painkillers after she complained of headaches and dizziness.

Then, in late 1996, she died at age 26 of a massive brain hemorrhage, and evidence suggests she may have suffered from a series of small brain bleeds.

"I blame myself so much for not making her go to another doctor," said her husband, Simi Valley truck mechanic Jerome Barry.

Just a few years ago, the Barry case would have represented nothing more than a routine, though tragic, claim of malpractice-a lawsuit not yet resolved in court: Gaines insists he did nothing wrong, and his attorney says medical records do not show a history of chronic headaches.

But in this year of $\mathrm{HMO}$ reform, it stands as a purported example of how HMO financial incentives to cut costs can interfere with a doctor's treatment of his patients-and as a reason that lawmakers, doctors, and patients are trying to change managed-care medicine.

Jerome Barry claims not only negligence, but that his wife was mistreated by Gaines because an HMO contract required the doctor to pay out of his own pocket for the costly special test the young mother needed, but never got. ${ }^{42}$

This anecdote, too, riveted attention on the plight of an individual, consistent with the three analytical perspectives and especially the ethic of care's concern with the particulars of such a plight. It also placed Norma Barry in the context of her relationship with her husband, who was obviously agonizing over her death, and a relationship of trust with her doctor-in keeping with both the communitarian ethic and the ethic of care. The account also drew readers toward the organizational/ institutional and professional levels because the example was placed in the context of the HMO reform debate that touched on business, medicine, and politics. This paragraph of context also implied concern with the justice of HMO interference in the treatment of patients.

Again, though, there are ethical problems, particularly in the fact that the anecdote, although couched in broader terms, may limit attention at the broader levels. Medical costs must be controlled. Because of the serious nature of medical problems, how costs are to be controlled becomes a profound issue of social ethics. Even though the story pointed to the broader issue of cost-cutting, exemplification research suggests that readers may better remember the individual, tragic case and thus miss the broader attention to economic reality. 
Daniel Callahan, a medical ethicist, sees the use of anecdotes as hindering consideration of broader resource questions. His comment regarding use of anecdotes in the assisted-suicide debate is also cautionary regarding HMO coverage and portrayal of other topics that involve social ethics: "I'm endlessly on programs with people who tell these sad stories, and it's very hard to talk about the larger social dangers of physician-assisted suicide when somebody's got a sad story." 43 The analysis of anecdotes about assisted suicide and HMOs bolsters the argument that anecdotes are ethically problematic if they ignore broader consideration of social-level concerns, such as just treatment of the terminally ill and just allocation of health care resources.

Applying the three analytical vantage points to the three examples suggests the importance of careful consideration of how and when anecdotes are to be used in news stories, especially against the backdrop of the exemplification literature's findings on the influence of exemplars. This section will suggest an approach that adapts the advantages of anecdotes but avoids some of their liabilities.

The suggestions for more critical thinking about choice of anecdotes arise out of an application of David Boeyink's discussion of use of casuistry in journalists' ethical decision making. ${ }^{44}$ Casuistry is an appropriate method here because it is case-based, as is anecdote choice. Casuists consider comparison of cases to be highly important in determining whether an action is morally justifiable. The anchor for the comparison and judgment is a paradigm case (or cases), in which the decision made is morally unambiguous. ${ }^{45}$ In classical Jesuit casuistry, such a case might involve a clear breach of the biblical command against killing. ${ }^{46}$ In terms of journalism ethics, it might mean taking an expensive gift from a news source - or, at the ethical end of the spectrum, accepting a free cup of coffee. ${ }^{47}$ In either realm of decision making, ambiguous cases are compared to clear-cut cases before choices are made. The choice of paradigm case thus becomes critical to the decision maker's understanding of the ethical issues at hand.

In situations in which reporters are striving to portray the ethical dimension of a news story, the notion of a paradigm case could be applied in two senses: anecdotes (cases) could be chosen to represent the possible extremes (the clearly ethical and the clearly unethical), or-in a twist on the notion of paradigm case-an anecdote could be chosen to represent the most morally ambiguous situation (as perceived in relationship to clear-cut cases). Without referring to casuistry, many reporters undoubtedly already seek to choose anecdotes that represent the ethical topics they are covering, and they focus on cases that highlight the difficult choices people face. However, the analysis in this article suggests that anecdotes could be used more appropriately if more conscious attention were given to how they represent the ethical issues in the situation being covered.

Two examples using stories about the topics discussed above will suggest more concretely how this adaptation of the use of casuistry could refine journalists' choices of anecdotes: 
1. Use of two anecdotes from "ethical extremes": a story on assisted suicide could use one anecdote that reflects a situation in which both opponents and proponents would come closest to seeing it as ethically unsupportable and one in which they would come closest to agreeing that it was supportable. The writer or TV reporter using this approach need not ignore the ethical concerns of opponents who would object even in this case, but by using this kind of template for choosing anecdotes, the reporter would reflect the breadth of viewpoints more fully.

A review of the body of stories on assisted suicide from which the case anecdote was taken did not show any single story with both kinds of anecdotes. However, examples of anecdotes that come close to reflecting both ethical extremes appeared in separate television stories. One depicted Emerson Hoogstraat, whose body was "in excruciating pain from bone cancer" and whose wife said, "He would go to bed at night and say to me, 'I hope I don't wake up in the morning.' ${ }^{\prime \prime 48}$ If this pain were too excruciating to be relieved, both sides would be closer to agreement on the appropriateness of assisted suicide than in other cases. Another story had an anecdote that portrayed Karen Mortensen, for whom better pain treatment had made her able to sleep at night and able to think about things other than dying. ${ }^{49}$ In this case, both sides might agree that assisted suicide would be inappropriate. Using both these anecdotes in one story would present the viewpoint spectrum.

This suggestion is not meant to imply that balance of ethical viewpoints should be the norm for all ethics coverage. In fact, writing which makes explicit a journalist's ethical views may do more for readers' understanding than ethical neutrality ${ }^{50}$ But this suggestion retains the notion that audience understanding is enhanced by exposure to more than one viewpoint.

2. Use of one anecdote with maximum moral ambiguity: a story about the practices of health maintenance organizations could use one anecdote that reflected the difficulty of moral choices involved by showing both ethical and unethical sides of HMOs. An ABC story about how to get the care one wants from an HMO focused on Cathy Patti, an Olympic skiing champion who had lost her right leg to cancer at age 9. She was initially denied the kind of prosthetic leg she needed, but eventually the company responded to her research and to her efforts to answer its questions by compromising on price with the prosthetic maker so she could get the leg, at no cost to her. The two sides in this case each individually represent clear-cut cases, but combined in one situation they reflect the ethical tension that arises in connection with HMOs.

Although this application of casuistry applies most directly to stories with a clear ethical dimension-such as stories on bioethical topics, or controversial practices in business or government-it also has implications for stories where ethics may not be as prominent. Use of anecdotes reflecting extremes of the positive or negative impact from a public issue, such as a city council decision on subdivision zoning, would help to paint a broad picture for readers or viewers. Similarly, an anecdote that reflected the most mixed impact would, in a different way, represent more than one side of the issue. 
Yet another way that journalists can personalize topics while keeping attention to their broadest dimensions is to accompany a broad issue piece with two or three sidebars, each centered on how the issue is playing out in the life of an individual or family. This idea of expanding anecdotes-personal stories-to full sidebars is not unfamiliar to journalists, but the use of more than one person-centered sidebar would broaden reader or viewer understanding of the impact of the issue beyond what might be gained from a single sidebar. In addition, applying the discussion of casuistry above to the choice of these "superanecdotes" - by using the notions of ethical extremes and maximum moral ambiguity-could help make journalistic portrayals more ethically balanced.

These sidebars could be written in third person like conventional news stories, with the sources cited, or they could be first-person pieces by the individuals themselves. In either case, they are consistent in particular with Gilligan's emphasis on the importance of relationships and voice. This approach can address the relationship dimension better than conventional anecdotes by shedding more detailed light on individuals and how they are wrestling through an issue such as genetic testing for a disease that runs in the family.

A sidebar with an issue piece from the first day of the Los Angeles Times series on HMOs noted earlier provides an excellent example of use of "super-anecdotes." The sidebar, headlined "Faces and Voices,"51 looked at the perspectives on HMOs of ten people including doctors, a nurse, and a hospital administrator. Each person was introduced in the reporter's voice; then each was quoted directly for several paragraphs, which empirical studies ${ }^{52}$ suggest will be more engaging to readers than paraphrasing. In addition, the series that day included a sidebar focusing on one surgeon. ${ }^{53}$ The ten-person sidebar provides one example of "maximum moral ambiguity": a cardiologist cites improvement in the quality of health care and greater accountability for time and resources, but also a deterioration in relationships among doctors and between them and patients as medicine becomes more competitive.

Training readers and viewers to expect anecdotes is problematic if stories without anecdotes are ignored or devalued. But, it is unrealistic to expect journalists to avoid using anecdotes, given their potential power to get the attention of readers and viewers. Thus, both journalists and researchers should think critically about the choice and use of anecdotes.

This analysis suggests that a good anecdote:

- Provides the fullest possible insight not merely about an individual but also about individuals in relationship with one another.

- Provides the fullest possible insight about the broader organizational, professional, and social contexts of a topic.

- Illustrates the tug of different viewpoints within the same situation or works with one or more other anecdotes to reflect multiple viewpoints. 
- Is not so highly emotional that it overshadows the broader point of a story.

These criteria suggest lines for further research. Additional studies growing out of this analysis could provide ethical evaluation of the use of anecdotes in larger sets of stories on a variety of topics, with an eye to how well the stories reflect these criteria. This kind of research would further the kind of critical analysis that can help bring readers and viewers stories that have both a powerful personal dimension and the context of social meaning.

\section{NOTES}

1. See, for example, Rhonda Gibson and Dolf Zillmann, "Exaggerated Versus Representative Exemplification in News Reports," Communication Research 21 (October 1994): 603-24; Charles F. Aust and Dolf Zillmann, "Effects of Victim Exemplification in Television News on Viewer Perception of Social Issues," Journalism \& Mass Communication Quarterly 73 (winter 1996): 787-803; Dolf Zillmann, Rhonda Gibson, S. Shyam Sundar, and Joseph W. Perkins Jr., "Effects of Exemplification in News Reports on the Perception of Social Issues," Journalism \& Mass Communication Quarterly 73 (summer 1996): 427-44; Dolf Zillmann and Hans-Bernd Brosius, Exemplification in Communication: The Influence of Case Reports on the Perception of Issues (Mahwah, NJ: Lawrence Erlbaum, 2000).

2. Gina Kolata, telephone interview by author, 29 April 1997.

3. David A. Craig, "A Framework for Evaluating Coverage of Ethics in Professions and Society," Journal of Mass Media Ethics 14 $(1,1999)$ : 1627.

4. Clifford G. Christians, John P. Ferre, and P. Mark Fackler, Good News: Social Ethics and the Press (NY: Oxford University Press, 1993).

5. Carol Gilligan, In a Different Voice: Psychological Theory and Women's Development (Cambridge, MA: Harvard University Press, 1982).

6. David E. Boeyink, "Casuistry: A Case-Based Method for Journalists," Journal of Mass Media Ethics 7 (2, 1992): 107-20.

7. See, for example, Shanto Iyengar, Is Anyone Responsible? How Television Frames Political Issues (Chicago: University of Chicago Press, 1991); Vincent Price, David Tewksbury, and Elizabeth Powers, "Switching Trains of Thought: The Impact of News Frames on Readers' Cognitive Responses," Communication Research 24 (October 1997): 481-506; Patti M. Valkenburg, Holli A. Semetko, and Claes H. de Vreese, "The Effects of News Frames on Readers' Thoughts and Recall," Communication Research 26 (October 1999): 550-69.

8. Iyengar, Is Anyone Responsible?

9. Valkenburg, Semetko, and de Vreese, "The Effects of News Frames."

10. Zillmann and Brosius, Exemplification in Communication.

11. Zillmann and Brosius, Exemplification in Communication, 5.

12. Daniel Kahneman and Amos Tversky, "On the Psychology of 
Prediction," Psychological Review 80 (July 1973): 237-51; M. Hammerton, "A Case of Radical Probability Estimation," Journal of Experimental Psychology 101 (December 1973): 252-54; Don Lyon and Paul Slovic, "Dominance of Accuracy Information and Neglect of Base Rates in Probability Estimation," Acta Psychologica 40 (August 1976): 287-98.

13. Ruth Hamill, Timothy DeCamp Wilson, and Richard E. Nisbett, "Insensitivity to Sample Bias: Generalizing From Atypical Cases," Journal of Personality and Social Psychology 39 (October 1980): 578-89.

14. Dolf Zillmann, Joseph Perkins, and S. Shyam Sundar, "Impression-Formation Effects of Printed News Varying in Descriptive Precision and Exemplifications," Medienpsychologie: Zeitschrift fur Individual- und Massenkommunikation 4(September 1992): 168-85, 239-40. Summarized in Zillmann and Brosius, Exemplification in Communication, 63-65.

15. Hans-Bernd Brosius and Anke Bathelt, "The Utility of Exemplars in Persuasive Communications," Communication Research 21 (February 1994): 48-78.

16. Zillmann et al., "Effects of Exemplification in News Reports."

17. Gibson and Zillmann, "Exaggerated Versus Representative Exemplification."

18. Aust and Zillmann, "Effects of Victim Exemplification."

19. Rhonda Gibson and Dolf Zillmann, "The Impact of Quotation in News Reports on Issue Perception," Journalism Quarterly 70 (winter 1993): 793-800.

20. Rhonda Gibson and Dolf Zillmann, "Effects of Citation in Exemplifying Testimony on Issue Perception," Journalism \& Mass Communication Quarterly 75 (spring 1998): 167-76.

21. See Zillmann and Brosius, Exemplification in Communication, for a detailed discussion of these studies.

22. Craig, "A Framework for Evaluating Coverage of Ethics," 17.

23. Commission on Freedom of the Press, A Free and Responsible Press (Chicago: University of Chicago Press, 1947); Fred. S. Siebert, Theodore Peterson, and Wilbur Schramm, Four Theories of the Press (Urbana, IL: University of Illinois Press, 1963); Wilbur Lang Schramm, Responsibility in Mass Communication (New York: Harper, 1957); William L. Rivers and Wilbur Schramm, Responsibility in Mass Communication, rev. ed. (New York: Harper \& Row, 1969); William L. Rivers, Wilbur Schramm, and Clifford G. Christians, Responsibility in Mass Communication, $3 \mathrm{~d}$ ed. (New York: Harper \& Row, 1980).

24. Christians, Ferre, and Fackler, Good News.

25. The framework has been applied to news about ethical controversies, but it is also relevant to news stories that are not specifically about ethical issues. David A. Craig, "Covering the Ethics of Death: An Exploration of Three Model Approaches" (paper presented at the annual meeting of AEJMC, Phoenix, AZ, 2000); David A. Craig, "Ethical Language and Themes in News Coverage of Genetic Testing," Journalism $\mathcal{E}$ Mass Communication Quarterly 77 (spring 2000): 160-74; David A. Craig, "Covering Ethics Through Analysis and Commentary: A Case Study,"Journal of Mass Media Ethics 17 (1,2002):53-68; David A. Craig and Vladan Pantic, "The Role of Questions in TVNews Coverage of the Ethics of Cloning" (paper presented at the annual meeting of AEJMC, Washing- 
ton, DC, 2001).

26. Christians, Ferre, and Fackler, Good News.

27. Christians, Ferre, and Fackler, Good News, 93.

28. Christians, Ferre, and Fackler, Good News, 93.

29. Meenakshi Gigi Durham, "On the Relevance of Standpoint Epistemology to the Practice of Journalism: The Case for 'Strong Objectivity,'"' Communication Theory 8 (May 1998): 117-40.

30. Gilligan, In a Different Voice.

31. Gilligan, In a Different Voice, 30.

32. Gilligan, In a Different Voice, 62.

33. Gilligan, In a Different Voice, 98.

34. The power of such anecdotes was evident in Craig's study of genetic testing coverage. See Craig, "Ethical Language and Themes."

35. Gilligan, In a Different Voice, 100.

36. The coverage included 21 stories on human embryo research, 98 on physician-assisted suicide, and 105 on HMOs. These groups of stories were previously chosen for other purposes.

37. The three anecdotes were not chosen using casuistry, as is proposed later in recommendations for journalistic practice, but because the anecdotes are more typical of conventional usage and because model anecdotes of the types proposed were rare in the coverage studied.

38. George Strait, news report, $A B C$ World News Tonight, 27 September 1994. Transcript retrieved from Lexis-Nexis online database.

39. Strait, news report, $A B C$ World News Tonight. Notes in brackets about visuals, in this and the other TV story in this analysis, were added by the author based on viewing of videotape from the Vanderbilt University Television News Archive.

40. Strait, news report, $A B C$ World News Tonight.

41. Mike Boettcher, news report, NBC Nightly News, 26 June 1997. Transcript retrieved from Lexis-Nexis online database.

42. Daryl Kelley, "Seeking a Cure: Patients, Doctors, Lawmakers Work for HMO Reform," Los Angeles Times, 28 July 1998, Part B, p. 1 (Ventura County Edition). Retrieved from Lexis-Nexis online database.

43. Daniel Callahan, telephone interview by author, 13 May 1997. See also Deni Elliott, "A Case of Need: Media Coverage of Organ Transplants," in Risky Business: Communicating Issues of Science, Risk, and Public Policy, ed. Lee Wilkins and Philip Patterson (New York: Greenwood Press, 1991), 151-58, a critical analysis of news coverage of an organ transplant case that received intense media attention in Maine.

44. Boeyink, "Casuistry: A Case-Based Method." For other discussions of casuistry in relation to journalism, see Sandra L. Borden, "Gotcha! Deciding When Sources Are Fair Game," Journal of Mass Media Ethics 10 (4, 1995): 223-35; Sandra L. Borden, "Character as a Safeguard for Journalists Using Case-Based Ethical Reasoning," International Journal of Applied Philosophy 13 (spring 1999): 93-104; Sandra L. Borden, "Janet Cooke in Hindsight: Reconsideration of a Paradigmatic Case in Journalism Ethics," Journal of Communication Inquiry 26 (April 2002): 155-70.

45. Boeyink, "Casuistry: A Case-Based Method." Boeyink draws on the discussion of casuistry in Albert R. Jonsen and Stephen Toulmin, The Abuse of Casuistry: A History of Moral Reasoning (Berkeley, CA: University 
of California Press, 1988) while noting that "definitions of casuistry have varied widely" (Boeyink, 112).

46. Jonsen and Toulmin, The Abuse of Casuistry, 252.

47. Boeyink, "Casuistry: A Case-Based Method," 112.

48. Aaron Brown, news report, $A B C$ World News Tonight, 8 January 1997. Transcript retrieved from Lexis-Nexis online database.

49. Jim Stewart, news report, CBS Evening News, 7 January 1997. Transcript retrieved from Lexis-Nexis online database.

50. Craig, "Covering Ethics Through Analysis and Commentary."

51. "Faces and Voices: Family Doctors, Specialists, Nurses, Hospital Administrators and HMO Care Givers Give Voices to Their Different Perspectives on HMO Medicine," Los Angeles Times, 26 July 1998, Part B, p. 2 (Ventura County Edition). Transcript retrieved from Lexis-Nexis online database.

52. Gibson and Zillmann, "The Impact of Quotation"; Gibson and Zillmann, "Effects of Citation."

53. Daryl Kelley, "Income Declines As Physician Turns Away HMO Patients," Los Angeles Times, 26 July 1998, Part B, p. 3 (Ventura County Edition). Transcript retrieved from Lexis-Nexis online database. 